\title{
Correction to: Hotel Revenue Management Strategy - Impacts and Consequences of Changes in Management
}

\author{
Antoine J. Bisson
}

\section{Correction to:}

Chapter 9 in: M. Sigala et al. (eds.), Case Based

Research in Tourism, Travel, Hospitality and Events, https://doi.org/10.1007/978-981-16-4671-3_9

The book was inadvertently published with an incorrect initial in author name as J. Bisson A. whereas it should be Bisson A.J. in online citation of the chapter. The correct citation has been updated. 